\title{
Toward the Use of Conceptual Metaphors of "Teacher" Perceived by High-school Students
}

\author{
Fariba Mansouri Koohestani \\ Payame Noor University, Rasht, Iran \\ Narjes Banou Sabouri \\ Department of Linguistics, Payame Noor University, Tehran, Iran \\ Parisa Farrokh \\ Islamic Azad University, Lahijan, Iran \\ Maryam Hessaby Dehbaneh \\ Alzahra University, Tehran, Iran
}

\begin{abstract}
This study is an attempt to find out the use of conceptual metaphors of teachers by the high-school students based upon Oxford et al. taxonomy (1988). In so doing, seventy participants were randomly selected among the high-school students of both genders aged 15 to 18 in Rezvanshahr - A city in Guilan province. The questionnaires were distributed required them to jot down their own conceptual metaphor about their teachers. The gathered information was analyzed through SPSS software after codifying. The results showed that most frequent class of metaphors used by them were "Learner-Centered Growth". It is meant that Iranian students like their teachers to be the facilitators who pave the way for them. On the other hand, there exists no significant relationship between gender and the type of metaphors that students use about their teachers.
\end{abstract}

Index Terms - cognitive semantics, conceptual metaphor, sociology of language, teacher

\section{INTRODUCTION}

In literature, metaphor is one of the most important literary terms and often causes complexity in literary texts and poetry. "Metaphor is everywhere in the language and there is no escape from it" (Goatly, 1997, p. 2). Language and in particular "speech is fundamentally metaphorical" (Murphy, 2001), Steuter \& Wills (2008) believed that "Through metaphor we make meaning; it helps us to understand problems and conflicts in certain ways, offering us certain available responses, and negating or obscuring others" (p. 3). Kövecses (2002) added that "trying to understand metaphor, then, means attempting to understand a vital part of who we are and what kind of world we live in" (p. xi).

Contrary to the ancient conceptions, metaphor is not only seen in poetry and literary texts. Our everyday speech, which is often neglected, has many metaphors that shape our intellectual and cultural system.

Metaphors are 'products of a cognitive activity' (Muller, 2008) and 'the mental processes it entails are basic to language and cognition'. Lakoff and his followers see metaphor as primarily a cognitive phenomenon. The support also is available by Santa Ana (2002) stated, "Metaphors provide the cognitive framework for worldview" (p. 21).

The systematicity of metaphor is another key point indicated by Steuter \& Wills (2008) that "metaphor operates concept to concept; it may have an experiential basis" (p. 35). Further support is available by Lakoff (1993) claimed "mappings are not arbitrary, but grounded in the body and in everyday experience and knowledge" (p. 39). Lakoff (cited in Levin, 1993) "used some objects like thermometers and stock market graphs to demonstrate the structure of metaphor in real life in a way that represented as being up and decreases as being down" (p. 241). Levin utilized them to serve as an experiential basis. Wormeli (2009) further confirmed that "metaphors are most commonly processed through the mind's eye; we can understand a topic because we can see it cognitively" (p. 4).

In the cognitive linguistic view, metaphors are sets of mappings between a more concrete source domain and a more abstract target domain. Kövecses (2002) noted that the source domains are typically more concrete or physical and more clearly delineated concepts than the targets. "Conceptual metaphors are unidirectional: they go from concrete to abstract domains" (Kövecses. 2010, p. 25).

Cognitive linguists (Gibbs, 1994; Johnson, 1987; Sweetser, 1990) believe that metaphor signifies the intellectualcultural system and shows how human beings interact with the world around them. When we apply metaphor, we are actually linking two conceptual systems based on similarity in the substitution of the word. This method of speech embraces the most basic of everyday issues up to the highest and most complex human thoughts. 
The present study seeks to examine the conceptual metaphors of the "teacher" used by high school students in the typology of Oxford et al. taxonomy (1998). Accordingly, four metaphorical perspectives toward teacher's classroom are Social Order, Cultural Transmission, Learner-Centered Growth and Social Reform.

The issue underlying the research is how the metaphorical notion of a teacher is in the mind of high school female and male students, and whether these metaphorical conceptions can be adapted to Oxford et al. taxonomy.

Oxford et al. (1998) investigated the use of metaphor for expressing different perspectives toward the teacher's concept. They used the metaphors produced by students and teachers about the teacher. They showed different and often conflicting metaphors about the teacher.

They emphasized in this paper that identifying and understanding these opposing views can enhance the teacher's insight, tolerance and understanding, and make the classroom warmer and more enjoyable for both the teacher and student.

A research carried out by Nikitana, \& Furuoka (2008) on the metaphors used by students about the teacher. They used quantitative methods to study the dimensions of given metaphors.

In this research, they used a questionnaire asking students to write their conceptual metaphors about their teachers and then analyzed the dimensions of these metaphors. The findings of this study confirmed the taxonomy of Oxford et al. (1998).

Pishghadam (2011) in his paper explored the metaphors that students have about language teachers, they then studied the given conceptual metaphors based on Martinez typology. The results of this analysis showed that students generally attribute their failures in learning to classroom behavior, while students of non-profit schools bound their success to the cognitive-related learning.

\section{THEORETICAL FRAMEWORK}

Conceptual metaphor theory indicates that the focus of metaphor is in concept, not in words; the source of metaphor is not based on similarity, but on the relations of the realm of simultaneous interconnections in the human experience and the understanding of the similarities of these domains.

Also, the major part of our conceptual system is metaphorical and includes deep and sustainable concepts such as time, events, causes, ethics, mind, and so on. These concepts are understood by multiple metaphors that have a rational concept (Gibbs \& Steun, 1997).

It can be said that the most fundamental claim of conceptual metaphor theory is that the human mental system is essentially metaphorical in nature. This theory states the reason why metaphors are so abundant in language; and that is they reflect the underlying metaphorical thoughts (Lakoff \& Johnson, 1980).

Our experiences of the outside world are of logical and natural basis for understanding the more abstract realm, and this is the reason why, in most cases, everyday metaphors of the source \& target domains are not substitutable. In other words, the orientation of conceptual metaphor is one-way and this is the principle of unindirectionality that is the movement of metaphor is from the more objective domain to the more abstract one, rather than the opposite (Kovecses. 2010).

It is important to distinguish between the metaphors that appear in our language and those that are the result of our thinking process. In conceptual metaphor, when we talk about the metaphors that appear in our language, we thereby mean linguistic metaphors or metaphorical phrases. Linguistic metaphor has two components that are subject and vector. The vector is what moves from one place to say something else (Kovecses. 2010).

Conceptual theory states that conceptual metaphors play an important role in the process of human thinking and are largely unconscious.

According to Lakoff and Johnson (1980), since communication is based on the same mental system that we use in thinking and acting, language can be an important source for knowing how this system works. Therefore, by examining language or more specifically, a group of linguistic metaphors that depict the internal system with a subject and vector, we face findings that other language theories cannot explain it in the same best way as conceptual metaphor.

Lakoff \& Johnson (1980) challenged the classic view of metaphor and claimed that metaphor is not only limited to language but it includes everyday lives of people in a way that the conceptual system of our day, on which we think and act, is fundamentally metaphorical. In so doing, metaphors not only shape our present life, but also determine our expectations of the future life (Lakoff \& Johnson, p. 3-5).

As Yu (2009) pointed out, cognitive metaphor is a complicated theory that requires various interactive components. These components are source domain and target domain (p. 30). Generally from the perspective of cognitive semantics, metaphor is the understanding of a conceptual domain based on another conceptual domain. This can be defined as "the conceptual domain of $\mathrm{A}$ is the conceptual domain of B". Thus, each conceptual metaphor is composed of two conceptual areas.

The domain where metaphorical terms are drawn to understand another conceptual domain is the source domain while the area that is understood in this way is the target domain. Therefore, in the metaphor of "life is a journey", life is the target, and journey is the source domain (Kövecses, 2010, p. 4). 
It must be noted that in conceptual metaphors, the more abstract notion is used as the target domain and the more objective concept as the target one that is precisely why contextual metaphors are often single-sided and elements are drawn from one domain to another.

\section{METHODOLOGY}

The constructivist/nonconstructivist distinction provides two alternative approaches to metaphor: for the constructivist, metaphor as an essential characteristic of the creativity of language; while from nonconstructivist position, metaphors are treated as rather 'unimportant, deviant, and parasitic on normal usage' (Ortony, 1993). Following this evidence is available from 'reductionist approach' (Black, 1993) that sees metaphorical utterances problematic or mysterious in a way that one might say, "If the metaphor producer did not mean what he said, why he did not say something else?” (p. 22).

This research is conducted for high-school boys and girls of Rezvanshahr in 2015. The participants were 70 students (35 girls \& 35 boys) aged 15 to 18 that were selected randomly. The researchers codified the data according to the taxonomy of Oxford et al. (1998). The frequency of metaphors was sought via descriptive statistics. SPSS software was used to study the relationship between the given metaphors and their genders.

Oxford et al. believed that metaphorical phrases used by the students about their "teacher" are classified into four typologies that are Social Order, Cultural Transmission, Learner-Centered Growth and Social Reform. From this perspective, those metaphors into the class of "Social order" consider "school" as a "production line" or a "factory system" where the "teacher" is a "technician" in the process of "social-engineering" and is responsible to educate students to combat social needs. In this regard, their conceptual metaphors are: producers, physician, mental and behavior controllers, etc.

Metaphors of Cultural Transmission type deals with the process of "enculturation or initiation into the historical practices and achievements of a given society". The related metaphors here are book, heart, and wizard.

The conceptual metaphor of "learner-centered growth" carries a meaning like "classroom proceedings and the learning process are distributed between the teacher and students" and the teacher should provide the conditions to cultivate the natural talents.

"social reforms" aims at creating a better society for all. Thus, a teacher can change the social criteria of a community like a reformer. This outlook would highlight some elements out of these three classes about "school \& teacher" and reach to the point that "the goal of a teachers is to mix and coordinate the needs of the community with the needs of individuals". In this view, the whole process of education is taken a new concept which is "interacting with life". In other words, the teacher and student should turn into a small "democratic miniature society" in which the teacher should help the development of society to be democratically, scientifically, and culturally advanced. Those conceptual metaphors of "teacher" placing in this category introduces them as "receiver" or "learning partner". Similar to the "learner-centered growth", teachers and learners in this category have control over the learning process.

\section{INSTRUMENTATION}

The main instrument of this study is a questionnaire composed of the incomplete sentence of "Teacher is a ....... Because he/she.......". To familiarize the respondents, the conceptual metaphor was defined first and some more examples were set. Then, they were asked to write their mental perception about their teacher and explain it in some words. Here is the answer sheet of respondents after being codified.

TABLE 1.

RESEARCH QUESTIONNAIRE

TYPE 1: SOCIAL ORDER

\begin{tabular}{|l|l|}
\hline The Teacher is..... & Because he/she........ \\
\hline a mason & makes beautiful sculptures and works of art over time from the students who are like the clay \\
\hline a chef & $\begin{array}{l}\text { Combines his/her knowledge, which is like a cooking ingredient, with experience that is as } \\
\text { favorable spices, and brings together the gourmet food of awareness that is delicious. }\end{array}$ \\
\hline a blacksmith & creates a valuable and beautiful thing from a student who looks like a solid and trashy iron \\
\hline a carpenter & casts, paints and prepares students who are like uncut and crumpled wood for the community. \\
\hline everything & Teaches you whatever you are void of and will form your character \\
\hline
\end{tabular}

TyPe 2: Cultural Transmission

\begin{tabular}{|l|l|}
\hline The Teacher is..... & Because he/she........ \\
\hline a book & is approachable and you can learn a lot from him/her whenever you like \\
\hline a white paper & $\begin{array}{l}\text { can like a white paper promote students with regular lines in the same way as the lines } \\
\text { of a paper regulate our writings on a white paper }\end{array}$ \\
\hline a useful book & $\begin{array}{l}\text { is full of scientific materials and notes, and if anyone wants, can get the benefit from } \\
\text { and if not, he can take the advantage. }\end{array}$ \\
\hline a rubber & $\begin{array}{l}\text { Would erase the wrong paths and makes the right choice in case a student makes a } \\
\text { mistake or misses the path }\end{array}$ \\
\hline a bee & puts a lot of effort into transferring knowledge to students \\
\hline
\end{tabular}


TYPE 3: LEARNER-CENTERED GROWTH

\begin{tabular}{|l|l|}
\hline The Teacher is..... & Because he/she........ \\
\hline a sailor & leads the students toward their goal in the same way a sailor drives the passengers to the destination \\
\hline a rain & $\begin{array}{l}\text { Keeps people away from ignorance with the help of knowledge in the way that raindrops save } \\
\text { humans from drought. }\end{array}$ \\
\hline a sun & is so radiant to bring the students to the height of knowledge. \\
\hline a mother & gives to students whatever a mother teaches to her child \\
\hline a candle & burns to lighten the society \\
\hline a gardener & works in the garden of community and cultivates the students who are like nice plants and flowers \\
\hline a sweeper & sweeps ignorance from the mind \\
\hline a sky & brings up students who are like plants \& flowers in efficacy \\
\hline a perfume & sprays all his/her knowledge over students \\
\hline a hen & makes students follow him/her into the land of knowledge \\
\hline a tree & grows like a tree and makes fruits that is the same as students \\
\hline a light & lightens the way for students \\
\hline a dock & shows the true way to the students \\
\hline a shepherd & guides the students like a shepherd \\
\hline a sea & is generous and gives students whatever he/she knows \\
\hline a shelter & protects students under his/her shadows \\
\hline a mosquito & sticks to the students to transfer knowledge \\
\hline a lake & waters the flowers and plants that are the students \\
\hline a lantern & shows the path to the student in darkness \\
\hline
\end{tabular}

\section{TYPE 4: SOCIAL REFORM}

\begin{tabular}{|l|l|}
\hline The Teacher is.... & Because he/she........ \\
\hline a hydrangea & $\begin{array}{l}\text { turns blue when the soil is acidic that some people love this color; it becomes pink } \\
\text { when the soil is alkaline and some other like this color }\end{array}$ \\
\hline a plant flower & can make the blossom flourish if he/she trains well, if not, the blossoms will die \\
\hline a book & $\begin{array}{l}\text { can arouse our interest turning us into an active listener if we like them but we do not } \\
\text { enjoy listening to them if we don't. }\end{array}$ \\
\hline a flower & withers away is we annoys him/her \\
\hline a tough math problem & is difficult to be understood but will make you pleased in communication \\
\hline a cactus & $\begin{array}{l}\text { is like a beautiful cactus if you do not tease him/her otherwise will hurt you with } \\
\text { his/her blades }\end{array}$ \\
\hline a sea anemone & $\begin{array}{l}\text { would sting if you do not get along well with him/her; if we listen well, seems pretty } \\
\text { and nice then }\end{array}$ \\
\hline a flower & dies as he/she withers away, so he/she must be appreciated \\
\hline glasses & shows the good \& bad of life better \\
\hline a mirror & expresses our strong \& weak points \\
\hline
\end{tabular}

\section{FINDINGS}

As Limputtong \& Ezzy (2005) stated, the first step in data analysis is the identification of the units of analysis i.e. units that enable the researcher to dismantle the data into digestible pieces. To find an appropriate answer for the research questions as well as confirming and rejecting the above hypothesis, the researchers descriptively analyzed the data based on student's pieces of respondents. Correlational Statistics and SPSS Software were then used for discovering the relationship between conceptual metaphor and gender.

\section{Testing Hypotheses}

H1. The most common conceptual metaphor used by the school girls about their teacher is "Cultural Transmission".

The first hypothesis is rejected in this study as the following table demonstrated that "Learner-centered growth" is the most common one instead.

TABLE 1.

FREQUENCY DISTRIBUTION OF DIFFERENT KINDS OF CONCEPTUAL METAPHORS IN SCHOOL GIRLS ABOUT “TEACHER"

\begin{tabular}{|l|l|l|}
\hline Type of Conceptual Metaphor & Number & Percent \\
\hline Learner-Centered Growth & 18 & $51 / 4$ \\
\hline Cultural Transmission & 7 & 20 \\
\hline Social Reform & 7 & 20 \\
\hline Social Order & 3 & $8 / 6$ \\
\hline Total & 35 & 100 \\
\hline
\end{tabular}

Analyzing the responses of school girls based on Oxford et al. taxonomy indicated that "Learner-centered Growth" with $51 / 4 \%$ is the most common kind of metaphor among the girls followed by "Cultural Transmission" and "Social Reform" with $20 \%$ each apiece. "Social Order" went as the final one with $8 / 6 \%$.

Teacher in the mind of a school girl is the provider of the conditions for more growth, a kind of situation which they are interested in. In this regard, the focus is on the full development of their potential talent.

H2. The most common conceptual metaphor used by the school boys about their teachers is "Social order". 
The second hypothesis is also rejected as Table 2 shows that the most common conceptual metaphor used by the school boys about their teacher is like the girls in the type of "Learner-centered growth" but with $77 / 1 \%$ higher than them followed by "social reform" with $14 / 3 \%$.

"Social Order" with 5/7\% and "Cultural Transmission" went as the final ones in this typology.

TABLE 2.

FREQUENCY DISTRIBUTION OF DIFFERENT KINDS OF CONCEPTUAL METAPHORS IN SCHOOL BOYS ABOUT “TEACHER”

\begin{tabular}{|l|l|l|}
\hline Type of Conceptual Metaphor & Number & Percent \\
\hline Learner-Centered Growth & 27 & $77 / 1$ \\
\hline Social Reform & 5 & $14 / 3$ \\
\hline Social Order & 2 & $5 / 7$ \\
\hline Cultural Transmission & 1 & $2 / 9$ \\
\hline Total & 35 & 100 \\
\hline
\end{tabular}

H3. There is a significant relationship between gender and the kind of metaphors that students used for their teachers.

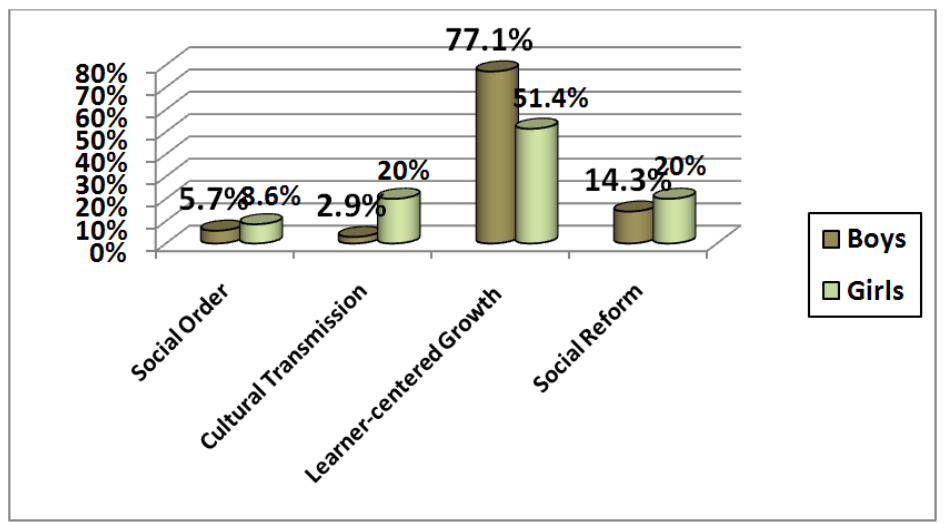

Graph 1. Relationship between Frequency Distribution of gender of students and the kind of metaphors used about the "teacher"

Fisher's Exact Test showed that there is no significant relationship statistically between the gender of high-school students and their selection of kinds of metaphor about "teacher" with 95\% confidence with the p-value of less than 5\% $(\mathrm{p}=0 / 074)$.

\section{CONCLUSION}

After completing the research and reviewing the findings, it was observed that among the four categories proposed by Oxford et al. (1998), the most effective conceptual metaphor produced by male and female students in this study was "Lerner-centered Growth" with $64.3 \%$. This implies that metaphors used by students mean that they want to participate in the classroom and involve themselves in teacher-student kind of interaction. $17 / 1 \%$ of the metaphors used by the students are from "social Reforms"; $11 / 4 \%$ of it are from "Cultural Transmission" and finally $7 / 1 \%$ are from "Social Order".

In previous studies particularly in the one done by Simsek (2014), most students produced their teacher-based metaphors. In the other words, $59 \%$ of the students used "social order" and "cultural transmission" types of metaphors in his study. It can be claimed that over half of the metaphors were teacher-based that is students accepted teacher as an all-round expert. According to Oxford et al. in "social order" kind of metaphor, the teacher builds the students to be efficient in society and school is like a factory where the teacher can make the frame of students in and form them. In "Cultural transmission", the teacher is as a guardian who knows everything and the students are void of anything. Thus, both of them are teacher-based as the teacher controls the mind and behavior; someone who completely controls the classroom. On the other side, $41 \%$ of students selected "learner-centered growth" type of metaphor.

Nikitina \& Furuoka (2008) in their research concluded that students have generally a positive perception toward their "language Teacher". They found that over half of the students $(66 / 7 \%)$ used "Learner-centered Growth" metaphors while $22 \%$ and $11 \%$ used respectively those metaphors related to "Cultural Transmission" and "Social Order". They (ibid) came to the point that Malaysian students expect the teacher to pave the way for them as a guide.

It is noteworthy to note that there were no such metaphors in "Social Reforms" category in none of the researches conducted by Simsek (2014) as well as Nikitina \& Furuoka (2008).

In fact, we can say that the results were influenced by the culture of society because previous learning experiences may not have prepared them for a democratic class interaction but rather for a hierarchical organization in which teachers are more respected and do not have an equal position as students.

This study signifies an important point that contrary to previous studies that in none of them "social reforms" type of metaphor was used about teacher, Iranian students used it and as the statistics shows, the most common one followed by the "learner-centered growth" was "social reforms". The why of not producing such type of metaphor in those previous 
studies (Nikitina \& Furuoka, 2008) roots in the culture of society. In "Social reforms" type, the teacher is "receiver" or "learning partner" and acts as a motivator, catalyzer, and receiver of various ideas.

This result here is along with the study of Nikitina \& Furuoka (2008) who confirms no significant relationship between gender and type of the produced metaphors.

\section{REFERENCES}

[1] Gibbs, R.W. (1994). The Poetics of Mind: Figurative, Thought, Language, and Understanding. New York: Cambridge University press.

[2] Gibbs, R.W. و \& Steun, G.J. (eds). (1997). Metaphor in Cognitive Linguistics, selected papers from the fifth international cognitive linguistics conference, Amsterdam: J. Benjamin's Co.

[3] Goatly, A. (1997). The Language of Metaphors. London: Routledge.

[4] Johnson, M. (1987). The Body in the Mind: The Bodily Basis of Reason and Imagination. Chicago: University of Chicago press.

[5] Kovecses, Z. (2002). Metaphor: A Practical Introduction. New York: Oxford University Press.

[6] Kovecses, Z. (2010). Metaphor a Practical Introduction. New York: Oxford university press.

[7] Lakoff, G. (1993). The Contemporary Theory of Metaphor. In A. Ortony (ed.) Metaphor and Thought (2 ${ }^{\text {nd }}$ ed.), Cambridge University Press.

[8] Lakoff, G., \& Johnson, M. (1980). Metaphors We Live by. Chicago: Chicago University Press.

[9] Levin, S. R. (1993). Language, concepts, and worlds: domains of metaphor. In A. Ortony (ed.) Metaphor and Thought ( $2^{\text {nd }}$ ed.), Cambridge University Press.

[10] Liamputtong, P., \& Ezzy, D. (2005). Qualitative Research Methods. Oxford: Oxford University Press.

[11] Muller, C. (2008). Metaphors Dead and Alive, Sleeping and Waking. Chicago: university of Chicago press.

[12] Murphy, P. F. (2001). Studs, Tools, and the Family Jewels: Metaphors Men Live By. USA: The University of Wisconsin Press.

[13] Nikitana, F., \& Furuoka, F. (2008). Measuring Metaphors: A Factor Analysis of Students' Conceptions of Language Teachers. Journal of Foreign Language Teaching [Electronic]. 5(2), pp.192-205.

[14] Ortony, A. (1993). Metaphor, language, and thought. In A. Ortony (ed.) Metaphor and Thought (2 ${ }^{\text {nd }}$ ed.), Cambridge University Press.

[15] Oxford, R. L., Tomlinson, S., Barcelos, A., Harrington, C., Lavine, R. Z., Saleh, A., \& Longhini, A. (1998). Clashing Metaphor about Classroom Teachers: Toward a Systematic Typology for the Language Teaching Field. System, 26(1), pp.3-50.

[16] Pishghadam, R., Hosseini, F. R., Askarzadeh, R., \& Navari, S. (2011). Qualitative Metaphor Analysis and Language Learning Opportunities. Iranian Journal of Applied Linguistics. Vol 14, No.1. pp. 77-108.

[17] Santa Ana, O. (2002). Brown Tide Rising: Metaphors of Latinos in Contemporary American Public Discourse. Austin: University of Texas Press.

[18] Simsek, M. R. (2014). A Metaphor Analysis of English Teacher Candidates Pre- and Post- Course Beliefs about Language and Teaching. Dicle Universitesi Ziya Gokalp EgitimFakultesi Dergisi. 22 (4). pp. 230-247.

[19] Steuter, E., \& Wills, D. (2008). At War with Metaphor. UK: Lexington Books

[20] Sweetser, E. (1990). From Etymology to Pragmatics: The Mind-as-body Metaphor in Semantic Structure and Semantic Change. Cambridge: Cambridge University Press.

[21] Wormeli, R. (2009). Metaphors Analogies; Power Tools for Teaching Any Subject. Maine: Stenhouse Publishers.

[22] Yu, N. (2009). The Chinese HEART in a Cognitive Perspective: Culture, Body, and Language (Applications of Cognitive Linguistics, vol. 12). Berlin and New York: Mouton de Gruyter.

Mansouri Koohestani was born in Iran in1971. She is a high-school teacher in Iran. She received her BA in teaching English from Guilan university and her MA in General Linguistics from Payam-e Noor University in Rasht. Her areas of interests are Language Teaching, Language Education, Applied Linguistics and Sociolinguistics.

Narjes Banou Sabouri is the assistant professor of Linguistics. She is also a faculty member in Department of Linguistics at Payam-e Noor University of Rudsar, Guilan, Iran. She has taught English courses for over eight years. She has delivered many international articles in teaching and linguistics in credentialed journals.

Parisa Farrokh holds Ph.D. in linguistics and she is an assistant professor at English Translation Department of Lahijan Islamic Azad University. She is interested in Discourse, Phonetics and Phonology.

Maryam Hessaby Dehbaneh was born in 1985 in Rasht. She is an MA holder of TEFL from Alzahra University. When she was 19, she experienced publishing her first book 'Let's Write English'. She enjoyed learning and researching independently as an undergraduate in Translation. Her areas of interest are Critical Literacy in the Iranian context, ESP, Material Development, Discourse and CALL. 